\title{
Influência da incorporação de resíduo de rocha ornamental sobre as propriedades e microestrutura sinterizada de piso cerâmico
}

\author{
Influence of the incorporation of ornamental rock waste \\ on the properties and sintered microstructure of floor tile
}

Souza, A. J., Pinheiro, B. C. A., Holanda, J. N. F.

Universidade Estadual do Norte Fluminense,

Grupo de Materiais Cerâmicos,

Avenida Alberto Lamego 2000, 28013-602 - Campos dos Goytacazes - RJ

e-mail: ajsouza@uenf.br; brunoc@uenf.br; holanda@uenf.br

\begin{abstract}
RESUMO
O Brasil é um dos maiores produtores e consumidores de rochas ornamentais no mundo. No entanto, a indústria de rochas ornamentais gera enormes quantidades de resíduos sólidos na forma de pó fino não biodegradável. No século XXI o grande desafio do setor de rochas ornamentais é o descarte final deste abundante resíduo de forma ambientalmente correta. Os resíduos de rochas ornamentais são ricos em materiais fundentes, que promovem a formação de fase líquida e auxiliam na densificação de materiais cerâmicos tradicionais. Neste trabalho foi avaliada a possibilidade de utilização de resíduo de rocha ornamental como um material de fluxo em composição para fabricação de piso cerâmico vitrificado de alta qualidade. As massas cerâmicas contendo até 45 \% em peso de resíduo de rocha ornamental foram preparadas pelo processo via seca. Peças cerâmicas prismáticas foram preparadas por prensagem uniaxial a $50 \mathrm{MPa}$ e sinterizadas a $1230{ }^{\circ} \mathrm{C}$ usando um ciclo de queima rápida. As seguintes propriedades física e mecânica foram determinadas: retração linear, absorção de água, massa específica aparente, porosidade aparente e tensão de ruptura a flexão. A microestrutura sinterizada foi acompanhada por microscopia eletrônica de varredura e as fases cristalinas foram identificadas por difração de raios-X. Os resultados mostram que o efeito da adição do resíduo de rocha ornamental foi o de promover maior densificação e propriedades melhoradas dos pisos cerâmicos vitrificados.
\end{abstract}

Palavras chaves:Resíduo de rocha ornamental, piso vitrificado, reciclagem.

\begin{abstract}
Brazil is one of the largest producers and consumers of ornamental rocks in the worldwide. However, the ornamental rock industry generates huge amounts of solid wastes in the form of not biodegradable fine powder. In the XXI century the great challenge of the ornamental rock industry is the final disposal of these abundant wastes in an environmentally correct way. The ornamental rock wastes are rich in flux materials, which promotes the formation of liquid phase and assist in the densification of traditional ceramics. In this study was evaluated the possibility of using ornamental rock waste as a flux material in composition for the production of ceramic floor tiles of high quality. The ceramic bodies containing up to $45 \%$ by weight of ornamental rock waste were prepared by dry process. Prismatic ceramic pieces were prepared by uniaxial pressing at $50 \mathrm{MPa}$ and sintered at $1230{ }^{\circ} \mathrm{C}$ using a fast-firing cycle. The following physical and mechanical properties were determined: linear shrinkage, water absorption, apparent density, apparent porosity and flexural strength. The sintered microstructure was accompanied by scanning electron microscopy and crystalline phases were identified by X-ray diffraction. The results show that the effect of the addition of ornamental rock waste was to promote higher density and improved properties of the vitrified ceramic floor tiles.
\end{abstract}


Keywords: Ornamental rock waste, vitrified floor tile, recycling.

\section{INTRODUÇÃO}

Atualmente o Brasil é um dos maiores produtores de rochas ornamentais (mármore e granito) do mundo. Essas rochas são extraídas da natureza em forma de blocos e enviadas a serrarias onde são cortadas em forma de lâminas para serem comercializadas [1]. Durante o processo de beneficiamento das rochas é gerada uma quantidade considerável de resíduos que misturados com a água usada para resfriamento se torna uma lama abrasiva. As lamas provenientes do setor de rochas ornamentais são em parte descartadas no meio ambiente sem nenhuma preocupação com a saúde pública. Elas podem ainda vir a atingir córregos e assorear rios. Estas lamas após secagem se transformam em um pó fino não biodegradável que passa a ser considerado um resíduo sólido. Destaca-se ainda o fato de que do ponto de vista ambiental, os resíduos sólidos do setor de rochas ornamentais são classificados como sendo classe II A - não inerte [2, 3]. Dessa forma, o setor de rochas ornamentais contribui para o passivo ambiental no cenário mundial.

Os resíduos de rochas ornamentais são materiais não plásticos ricos em óxidos como $\mathrm{K}_{2} \mathrm{O}$, $\mathrm{NaO}$ e $\mathrm{CaO}$, que promovem a formação de fase líquida e auxiliam na densificação de materiais cerâmicos tradicionais [4]. Isto torna estes resíduos atrativos para incorporação como um material de fluxo na composição da massa cerâmica para fabricação de piso cerâmico vitrificado. Estes pisos são fabricados a partir de uma composição de massa triaxial do tipo caulim/material fundente/quartzo [5]. Os materiais fundentes mais utilizados na indústria de revestimento cerâmico são o feldspato sódico e feldspato potássico [6]. Por outro lado, a indústria de revestimento cerâmico brasileira tem apresentado grande crescimento e destaque no cenário mundial. Isto tem levado ao aumento da demanda por feldspatos [7]. A alta demanda e possibilidade de escassez de feldspatos tem levado a busca de novos materiais fundentes. Neste contexto, os resíduos de rochas ornamentais podem ser uma alternativa tecnológica e econômica viável como substituto parcial de feldspatos em formulações de massas para pisos cerâmicos vitrificados. Verificase também que no Brasil pouca atenção tem sido dada sobre a possibilidade de formulação de massas cerâmicas contendo resíduo de rocha ornamental visando à fabricação de pisos cerâmicos vitrificados.

Neste trabalho foi feito um estudo com o objetivo de avaliar a influência da incorporação de resíduo de rocha ornamental proveniente do estado do Rio de Janeiro nas propriedades tecnológicas e microestrutura sinterizada de piso cerâmico vitrificado.

\section{MATERIAIS E MÉTODOS}

Neste trabalho foram utilizadas as seguintes matérias-primas: caulim, feldspato sódico (albita), resíduo de rocha ornamental e quartzo. A Tabela 1 apresenta as composições químicas e de fases das matérias-primas utilizadas. A massa cerâmica de referência foi previamente formulada por Pinheiro [8]. As demais massas cerâmicas foram formuladas a partir da substituição gradual da albita por resíduo de rocha ornamental, conforme mostrado na Tabela 2.

Tabela 1: Composições químicas (\% em peso) e de fases das matérias-primas.

\begin{tabular}{l|l|l|l|l}
\hline \multicolumn{1}{c|}{ ÓXIDOS } & \multicolumn{1}{c|}{ CAULIM } & \multicolumn{1}{c}{ QUARTZO } & \multicolumn{1}{c}{ ALBITA } & \multicolumn{1}{c}{ RESÍDUO } \\
\hline $\mathrm{SiO}_{2}$ & 49,07 & 98,97 & 69,55 & 66,43 \\
\hline $\mathrm{Al}_{2} \mathrm{O}_{3}$ & 33,74 & 0,41 & 18,22 & 17,49 \\
\hline $\mathrm{Fe}_{2} \mathrm{O}_{3}$ & 0,22 & \multicolumn{1}{c}{$<0,01$} & 0,14 & 3,80 \\
\hline $\mathrm{TiO}_{2}$ & $<0,01$ & 0,019 & 0,017 & 0,83 \\
\hline $\mathrm{CaO}$ & 0,30 & $<0,01$ & 0,17 & 2,23 \\
\hline $\mathrm{MgO}$ & 0,061 & $<0,01$ & 0,09 & - \\
\hline $\mathrm{K}_{2} \mathrm{O}$ & 1,97 & 0,18 & 1,47 & 8,50 \\
\hline $\mathrm{Na}{ }_{2} \mathrm{O}$ & 0,52 & 0,13 & 9,63 & - \\
\hline $\mathrm{MnO}$ & - & - & - & 0,07 \\
\hline P.F. & 14,01 & 0,26 & 0,32 & 0,65 \\
\hline Fases cristalinas & $\begin{array}{l}\text { caulinita, quartzo e } \\
\text { mica }\end{array}$ & quartzo & albita e quartzo & $\begin{array}{l}\text { quartzo, mica, microclina, } \\
\text { albita, hematita e calcita }\end{array}$ \\
\hline
\end{tabular}


Tabela 2: Composição das massas cerâmicas (\% em peso).

\begin{tabular}{l|l|l|l|l}
\hline \multicolumn{1}{c|}{ MASSA CERÂMICA } & \multicolumn{1}{|c|}{ CAULIM } & \multicolumn{1}{c|}{ ALBITA } & \multicolumn{1}{c}{ RESÍDUO } & \multicolumn{1}{c}{ QUARTZO } \\
\hline MR & 40 & 47,5 & 0 & 12,5 \\
\hline M10 & 40 & 37,5 & 10 & 12,5 \\
\hline M20 & 40 & 27,5 & 20 & 12,5 \\
\hline M30 & 17,5 & 30 & 12,5 \\
\hline M40 & 40 & 7,5 & 40 & 12,5 \\
\hline M47,5 & 40 & 0 & 47,5 & 12,5 \\
\hline
\end{tabular}

As massas cerâmicas foram preparadas pelo processo de granulação por via seca. As matérias-primas foram moídas a seco utilizando-se um moinho de bolas de porcelana, separadamente, até atingirem tamanho de partícula inferior a 325 mesh (45 $\mu \mathrm{m}$ ABNT) [9]. As massas cerâmicas foram misturadas em misturador cilíndrico por 30 min. Em seguida foram granuladas manualmente em peneira 40 mesh (420 $\mu \mathrm{m}$ ABNT) com $7 \%$ de umidade e colocadas em dessecador, onde ficaram por $24 \mathrm{~h}$ para garantir a homogeneidade da umidade.

As peças cerâmicas foram produzidas por prensagem uniaxial sob pressão de $50 \mathrm{MPa}$, numa matriz de aço com cavidade retangular $\left(11,50 \times 2,54 \times 0,75 \mathrm{~cm}^{3}\right)$. As peças conformadas foram posteriormente secas em estufa $\left(110{ }^{\circ} \mathrm{C}\right.$ por $\left.24 \mathrm{~h}\right)$. O processo de sinterização foi realizado a temperatura de patamar de $1230{ }^{\circ} \mathrm{C}$ em um forno elétrico de laboratório, usando-se um ciclo de queima rápida (<60 min.).

As seguintes propriedades física e mecânica foram determinadas utilizando-se procedimentos padronizados: retração linear, absorção de água, massa específica aparente, porosidade aparente e tensão de ruptura a flexão em carregamento três pontos. A identificação das fases cristalinas nas peças cerâmicas sinterizadas foi feita por difração de raios-X (Difratômetro Shimadzu, modelo XRD-700). A microestrutura da superfície de fratura das amostras foi examinada via imagens de elétrons secundários em um microscópio eletrônico de varredura (Shimadzu, modelo SSX-550).

\section{RESULTADOS E DISCUSSÃO}

As Figuras 1-3 apresentam os difratogramas de raios-X das peças cerâmicas sinterizadas a $1230{ }^{\circ} \mathrm{C}$ para as formulações MR, M20 e M47,5, respectivamente. Observa-se que as três formulações analisadas apresentam difratogramas muito similares. As principais fases cristalinas presentes em todas as formulações estudadas são: mullita primária $\left(2 \mathrm{Al}_{2} \mathrm{O}_{3} \cdot 2 \mathrm{SiO}_{2}\right)$, quartzo e cristobalita. Os resultados também mostram que quando a temperatura foi elevada da temperatura ambiente até $1230^{\circ} \mathrm{C}$ uma série de transformações físico-químicas ocorreu durante a sinterização. A caulinita presente no caulim (Tabela 1) se decompôs para formar a mullita primária [10], o feldspato sódico fundiu para formar a fase líquida que quando resfriada se transforma em vidro e uma parte do quartzo se transformou em cristobalita ou se dissolveu na fase líquida. Assim, a substituição gradual do material fundente natural (feldspato sódico) por resíduo de rocha ornamental não resultou em qualquer influência óbvia na evolução das fases cristalinas dos pisos cerâmicos vitrificados. O resíduo de rocha ornamental que é rico em óxidos fundentes $\left(\mathrm{K}_{2} \mathrm{O}+\mathrm{Fe}_{2} \mathrm{O}_{3}+\mathrm{CaO}\right)$ provavelmente leva a formação de fase líquida em menor temperatura e de menor viscosidade. 


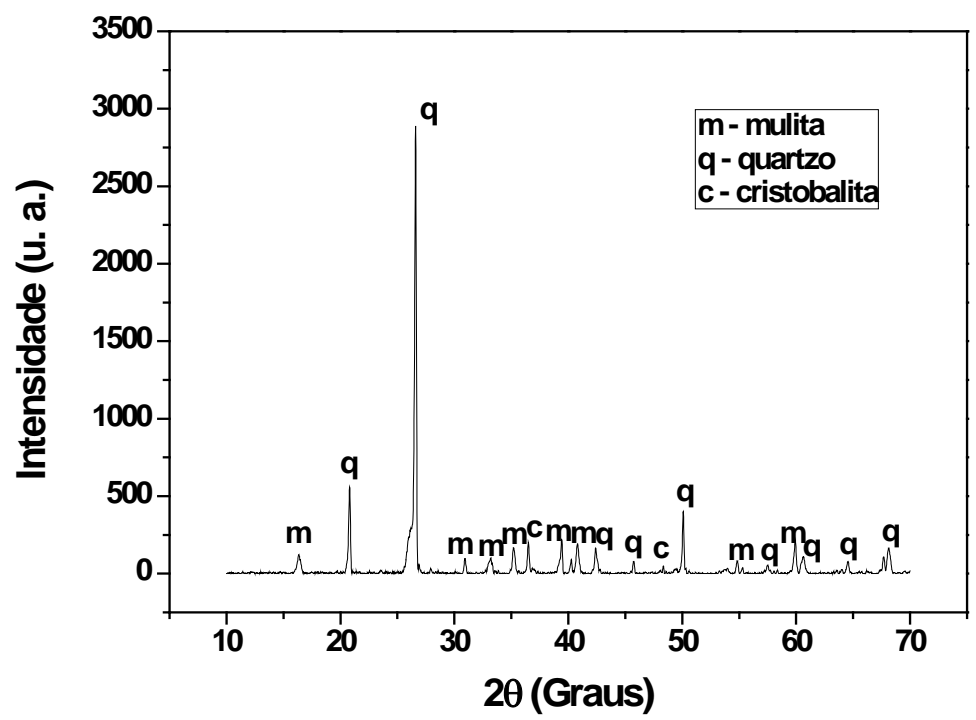

Figura 1: Difratograma de raios-X da formulação MR sinterizada a $1230{ }^{\circ} \mathrm{C}$.

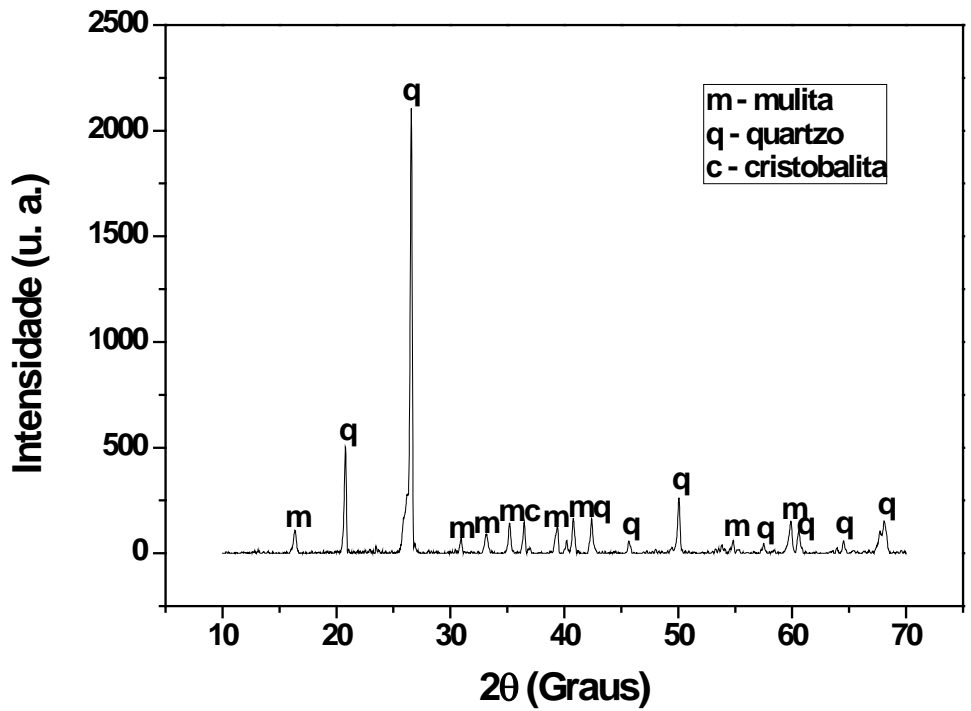

Figura 2: Difratograma de raios-X da formulação M20 sinterizada a $1230{ }^{\circ} \mathrm{C}$. 


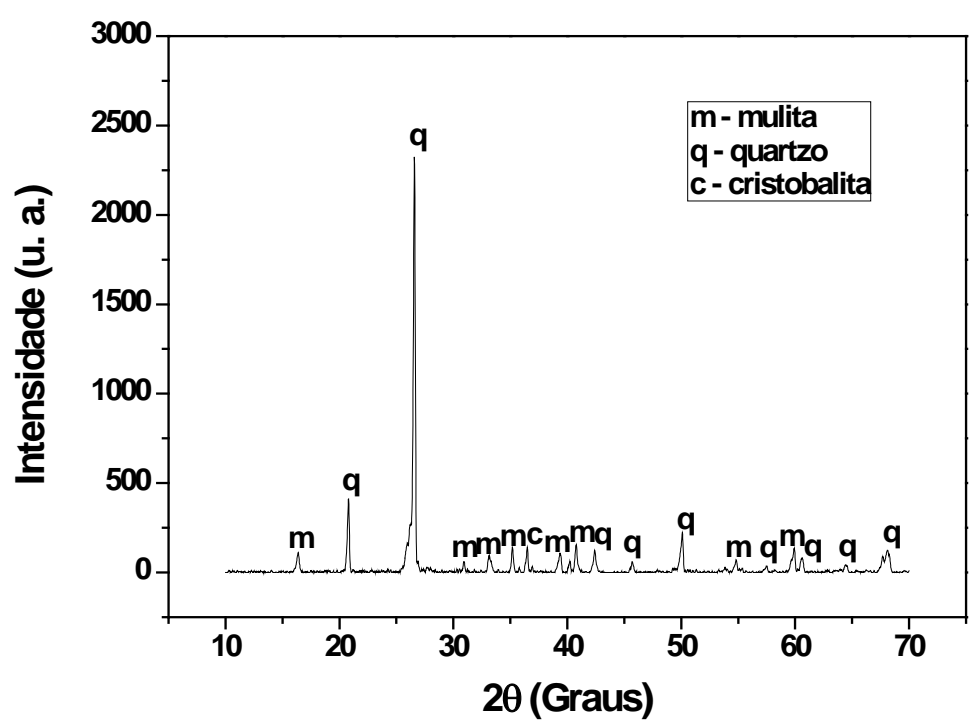

Figura 3: Difratograma de raios-X da formulação M47,5 sinterizada a $1230{ }^{\circ} \mathrm{C}$.

Nas Figuras 4a-c são apresentadas as superfícies de fratura das peças cerâmicas sinterizadas. O efeito da adição do resíduo de rocha ornamental é evidente. Na Figura 4a observa-se que a superfície de fratura correspondente à massa cerâmica de referência MR é bastante densa e vitrificada. No entanto, observa-se também a presença de uma fina porosidade aberta na estrutura das peças cerâmicas. Com a adição do resíduo de rocha ornamental, como mostrado nas Figuras $4 \mathrm{~b}$ e 4c, a microestrutura da superfície de fratura evolui para uma textura mais suave e alto grau de densificação. A porosidade aberta foi praticamente eliminada para a formulação M47,5, que corresponde a substituição total do feldspato sódico pelo resíduo de rocha ornamental. Isto demonstra que o resíduo de rocha ornamental é mais efetivo na vitrificação e densificação dos pisos cerâmicos, provavelmente devido à formação de um maior volume de fase líquida de menor viscosidade [11].
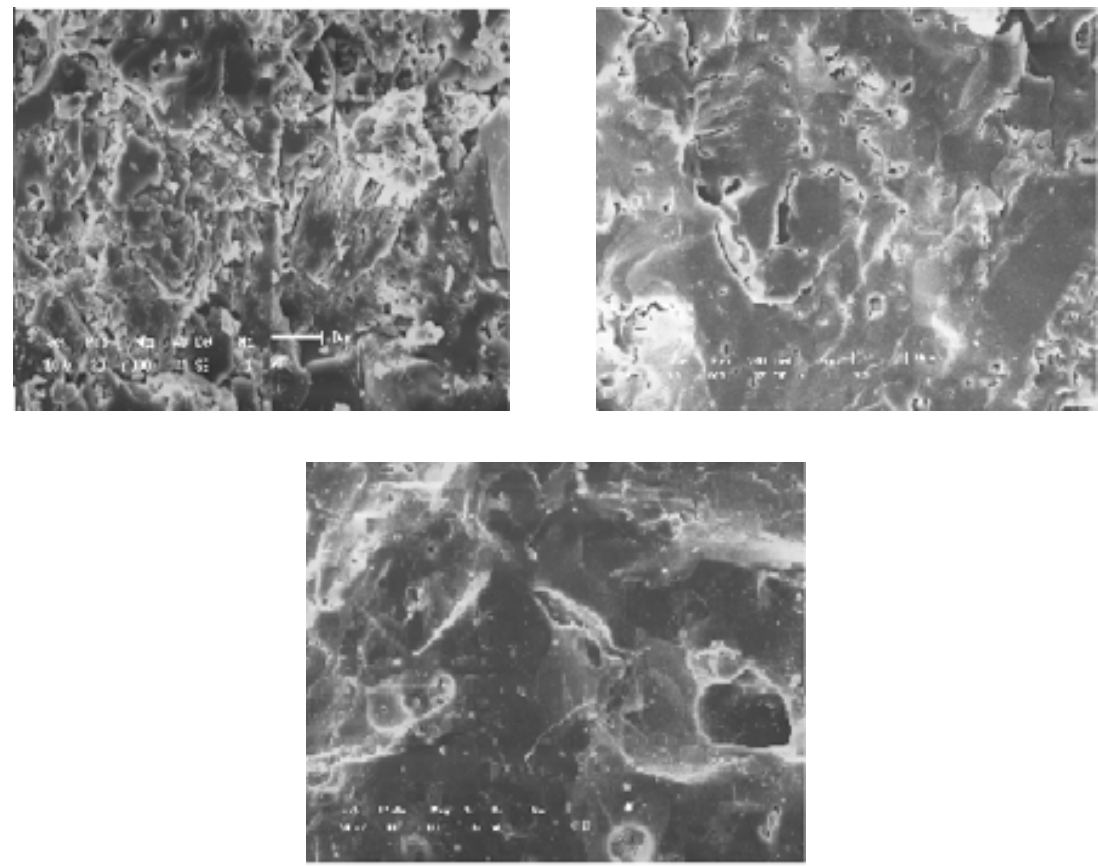

Figura 4: Microestruturas dos pisos cerâmicos sinterizados a $1230{ }^{\circ} \mathrm{C}$ : (a) MR; (b) M20; e (c) M47,5. Aumento de 1000x. 
A Figura 5 apresenta a retração linear das peças cerâmicas sinterizadas a $1230{ }^{\circ} \mathrm{C}$. Os resultados mostram que a incorporação do resíduo de rocha ornamental, em substituição ao feldspato potássico (albita), na composição das massas cerâmicas, teve uma forte influência na retração linear. Isto se deve a formação de fase líquida promovida pelo resíduo de rocha ornamental durante a sinterização. Pode-se observar também que os valores de retração linear na faixa de 6,06 - 9,58 \% estão dentro da faixa adequada para fabricação industrial de pisos cerâmicos vitrificados de alta qualidade.

Na Figura 6 é apresentada à absorção de água das peças cerâmicas sinterizadas a $1230{ }^{\circ} \mathrm{C}$. Nota-se uma queda significativa nos valores de absorção de água das peças cerâmicas. Isso ocorre devido ao fato de o resíduo de rocha ornamental ser rico em óxidos fundentes $\left(\mathrm{K}_{2} \mathrm{O}+\mathrm{Fe}_{2} \mathrm{O}_{3}+\mathrm{CaO}\right)$, que promove a formação de fase líquida de menor viscosidade, eliminando assim a porosidade aberta no interior das peças cerâmicas. As formulações M30, M40 e M47,5 apresentam valores de absorção de água muito baixos < 0,5 \%.

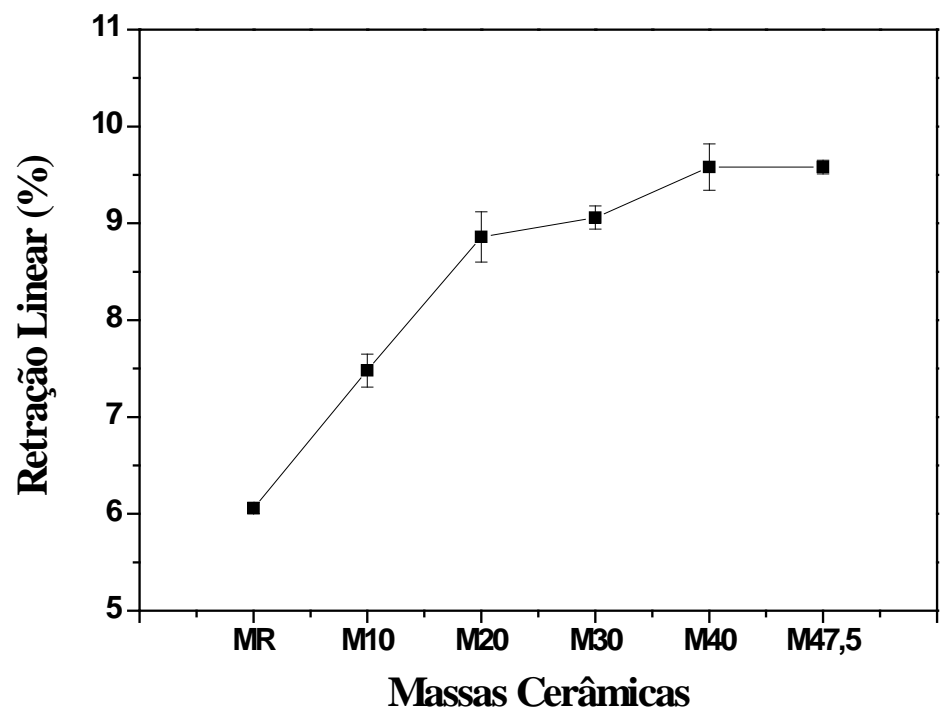

Figura 5: Retração linear das peças cerâmicas sinterizadas a $1230^{\circ} \mathrm{C}$.

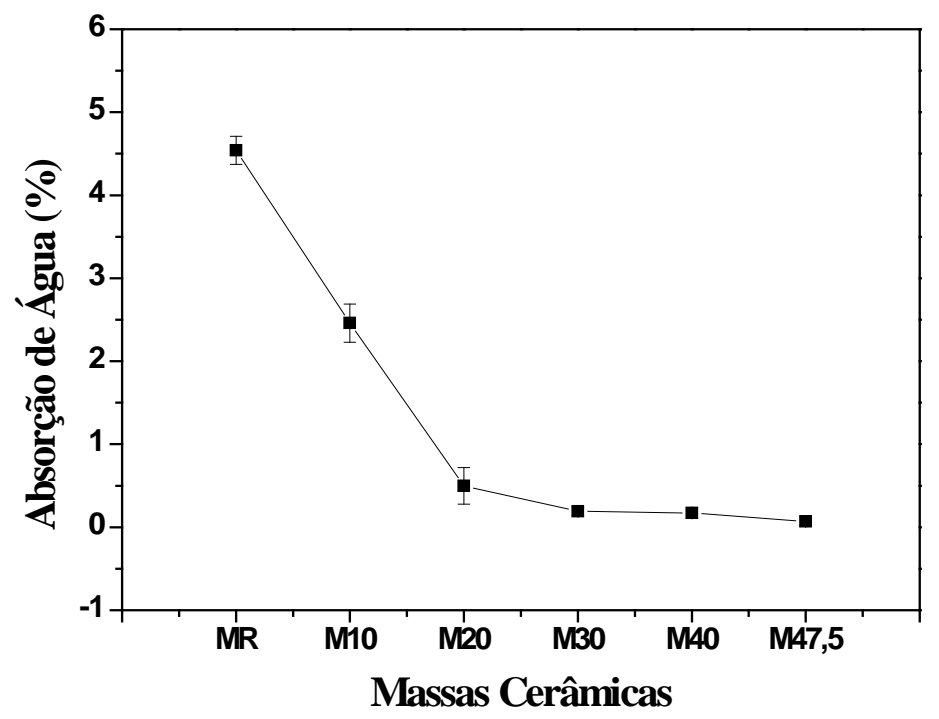

Figura 6: Absorção de água das peças cerâmicas sinterizadas a $1230^{\circ} \mathrm{C}$. 
Na Figura 7 é apresentado o comportamento da massa específica aparente das peças cerâmicas em função do teor de resíduo de rocha ornamental adicionado. Verifica-se que, com o aumento gradual do percentual de resíduo adicionado às massas cerâmicas, ocorrem aumentos significativos nos valores de massa específica aparente $\left(2,24-2,45 \mathrm{~g} / \mathrm{cm}^{3}\right)$. Este comportamento é consistente com a densificação das peças cerâmicas provocada pela ação fundente do resíduo de rocha ornamental, que elimina grande quantidade de porosidade da estrutura. Este resultado é corroborado pela porosidade aparente das peças sinterizadas (Figura 8). Por exemplo, a formulação M47,5 atinge um valor de porosidade próximo de zero assemelhando-se ao comportamento observado para a absorção de água.

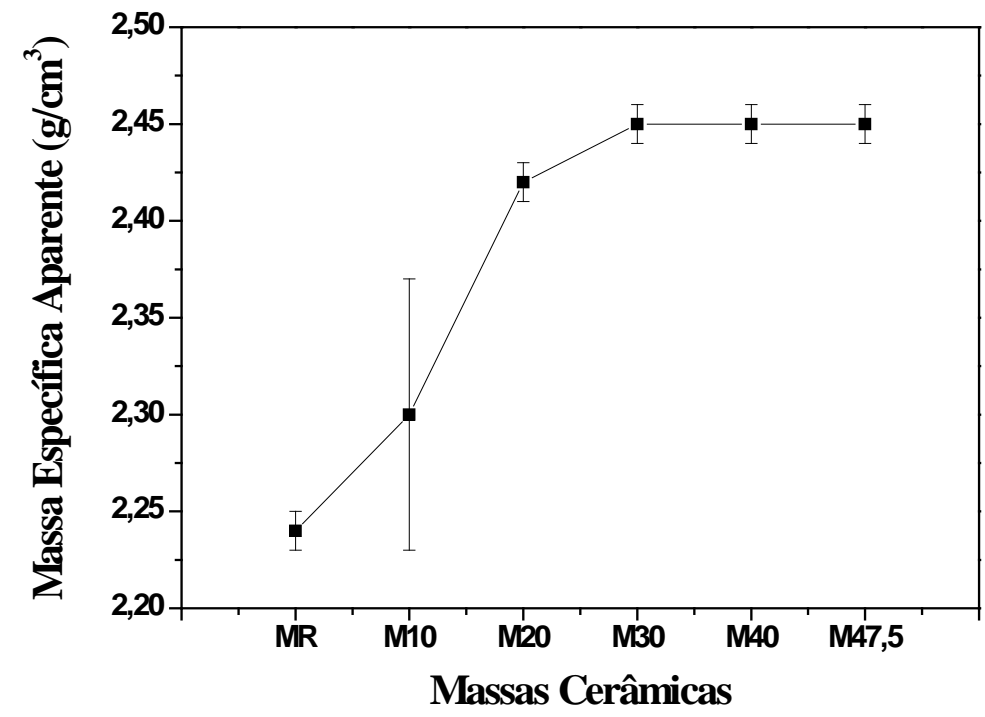

Figura 7: Massa específica aparente das peças cerâmicas sinterizadas a $1230{ }^{\circ} \mathrm{C}$.

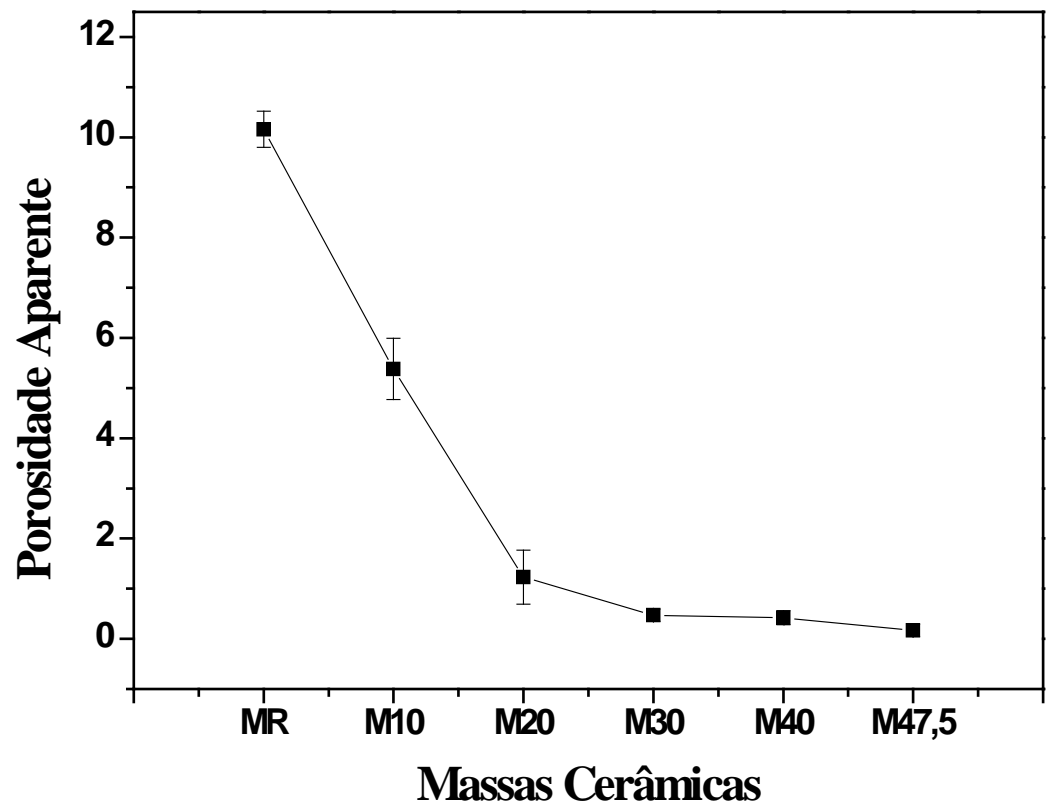

Figura 8: Porosidade aparente das peças cerâmicas sinterizadas a $1230^{\circ} \mathrm{C}$. 
A Figura 9 apresenta o efeito da composição da massa cerâmica sobre a tensão de ruptura à flexão das peças cerâmicas. Pode-se observar que a substituição gradual do feldspato sódico pelo resíduo de rocha ornamental resulta no melhoramento da resistência mecânica das peças cerâmicas. Os valores de tensão de ruptura a flexão na faixa de 38,40 - 67,18 MPa são adequados para fabricação industrial de pisos cerâmicos vitrificados. Este comportamento se deve fundamentalmente a densificação das peças cerâmicas. Além disso, os dados de resistência mecânica estão bem correlacionados com as demais propriedades físicas (retração linear, absorção de água, massa específica aparente e porosidade aparente) e microestrutura sinterizada dos pisos cerâmicos vitrificados.

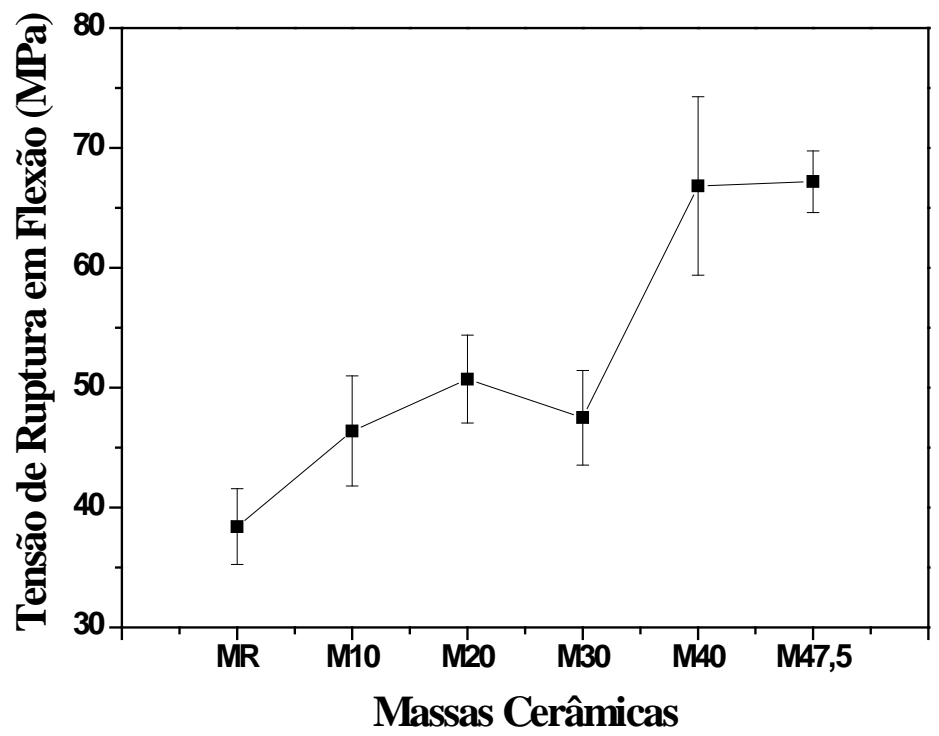

Figura 9: Tensão de ruptura a flexão das peças cerâmicas sinterizadas a 1230 C.

Uma importante questão é a viabilidade do uso industrial das massas cerâmicas estudadas para fabricação de piso cerâmico vitrificado. Neste contexto, duas propriedades são normalmente utilizadas em normas técnicas para classificação de pisos cerâmicos: absorção de água (AA) e tensão de ruptura á flexão $(\sigma)$. De acordo com a norma ABNT NBR 13818 [12] os revestimentos cerâmicos para pisos são classificados como: Grês Porcelanato - Grupo BIa (AA $\leq 0,5 \%$; $\sigma \geq 35 \mathrm{MPa}$ ); Grês - Grupo BIb $(0,5<\mathrm{AA}$ $\leq 3,0 \% ; \sigma \geq 27 \mathrm{MPa})$; Semi-Grês - Grupo BIIa (3,0<AA $\leq 6,0 \% ; \sigma \geq 27 \mathrm{MPa})$; e Semi-Poroso Grupo BIIb (6,0 < AA $\leq 10,0 \% ; \sigma \geq 22 \mathrm{MPa})$. Na Tabela 3 são apresentados os possíveis tipos de pisos cerâmicos vitrificados que poderiam ser fabricados com as massas cerâmicas formuladas com resíduo de rocha ornamental.

Tabela 3: Tipos de pisos vitrificados para as massas cerâmicas sinterizadas a $1230{ }^{\circ} \mathrm{C}$.

\begin{tabular}{l|c}
\hline \multicolumn{1}{c|}{ MASSAS } & TIPO DE PISO VITRIFICADO \\
\hline MR & BIIa \\
\hline M10 & BIb \\
\hline M20 & BIa \\
\hline M30 & BIa \\
\hline M40 & BIa \\
\hline M47,5 & BIa \\
\hline
\end{tabular}


Os resultados da Tabela 3 mostram que à medida que o resíduo de rocha ornamental vai substituindo o feldspato sódico na formulação da massa cerâmica de referência são obtidos pisos de melhor qualidade técnica. Para as condições estudadas a massa cerâmica de referência (MR) permite a obtenção de piso do tipo BIIa, ou seja, piso do tipo semi-grês. Quando 10 \% em peso do feldspato sódico foi substituído pelo resíduo (formulação M10), a qualidade do piso evoluiu de piso do tipo BIIa (formulação MR) para piso do tipo BIb, ou seja, piso do tipo grês. Verifica-se também que para adições de resíduo a partir de $20 \%$ em peso (formulações M20, M30, M40 e M47,5) são obtidos pisos cerâmicos vitrificados de alta qualidade técnica, ou seja, são obtidos pisos do tipo grês porcelanato (BIa). Isto é muito importante devido o grês porcelanato ser o tipo de piso líder no mercado mundial de revestimentos cerâmicos.

\section{CONCLUSÕES}

Os resultados experimentais indicam que a adição de resíduo de rocha ornamental em substituição do feldspato sódico (albita) influencia diretamente na microestrutura e propriedades tecnológicas de pisos cerâmicos vitrificados. Em geral, tem-se uma microestrutura muito densa e vitrificada com a adição de resíduo de rocha ornamental, embora não ocorra modificação na composição das fases cristalinas presentes nas peças cerâmicas sinterizadas a $1230{ }^{\circ} \mathrm{C}$.

As propriedades tecnológicas (retração linear, absorção de água, massa específica aparente, porosidade aparente e tensão de ruptura a flexão) das peças sinterizadas foram significativamente modificadas, causando uma mudança na qualificação do tipo de piso cerâmico. Foi obtido piso do tipo grês porcelanato (BIa) para as massas M20, M30, M40 e M47,5. Portanto, o reuso de resíduo de rocha ornamental na fabricação de pisos vitrificados não somente contribui para dar um destino correto para este abundante resíduo, como também contribui para maximizar a qualidade técnica do produto cerâmico.

\section{AGRADECIMENTOS}

Os autores agradecem ao CNPq e FAPERJ pelo apoio financeiro.

\section{BIBLIOGRAFIA}

[1] ALMEIDA, S.L.M., CHAVES, A.P., LEAL FILHO, L.S, "Primera jornadas Iberoamericanas sobre caracterización y normalización de materiales de construcción”, Programa CYTED, Madrid: Espanha, 2001.

[2] MOTHÉ FILHO, H.F., POLIVANOV, H., MOTHÉ, C.G., "Reciclagem de resíduos sólidos de rochas ornamentais”, Anuário do Instituto de Geociências, v. 28-2, pp. 139-151, UFRJ, Rio de Janeiro, RJ, Brasil 2005.

[3] MANHÃES, J.P.V.T., HOLANDA, J.N.F., “Caracterização de resíduo sódico de pó de rocha granítica gerado na indústria de rochas ornamentais”, Química Nova, v. 31, n. 6, pp. 1301-1304, 2008.

[4] SEGADÃES, A.M., CARVALHO, M.A., ACCHAR, W., "Using marble and granite rejects to enhance the processing of clay products”, Applied Clay Science, v. 30, n. 1, pp. 42-52, 2005.

[5] SANCHEZ, E., ORTS, M.J., GARGIA-TEM J., et al., "Efeito da composição de matérias-primas empregadas na fabricação de grés porcelanato sobre as fases formadas durante a queima e as propriedades do produto final”, Cerâmica Industrial, v. 6, n. 5, pp. 15-22, set./out. 2001.

[6] RODRIGUEZ, A.M., PIAMARO, S.A., BERG, E.A., et al., "Propriedades de matérias-primas selecionadas para produção de grés porcelanato”, Cerâmica Industrial, v. 9, n. 1, PP. 33-38, jan./fev. 2004.

[7] LENGLER, H.C.M., BRAGANÇA, S.R., BERGMANN, C.P., "Influência do Tipo de Fundente Sobre a Porosidade Final em Cerâmicas Tradicionais”, Anais do $17^{\circ}$ Congresso Brasileiro de Engenharia e Ciência dos Materiais, Foz do Iguaçu, PR, Brasil, pp. 560-570, 2006.

[8] PINHEIRO, B.C.A., Influência do resíduo borra de petróleo encapsulada em massas cerâmicas para grés porcelanato, Tese de D. Sc, CCT/UENF, Campos dos Goytacazes, RJ, Brasil, 2008.

[9] ASSOCIAÇÃO BRASILEIRA DE NORMAS TÉCNICAS - ABNT: NBR 7181-84, Análise granulométrica. Rio de Janeiro, 1984.

[10] SOUZA, A.J., Estudo da substituição de fundente natural por resíduo de rocha ornamental em massa cerâmica para piso vitrificado, M. Sc. CCT/UENF, Campos dos Goytacazes, RJ, Brasil, 2008. 
[11] RIELLA, H.G., FRNJNDLICH, E.U.C., DURAZZO, M., “Caracterização e utilização de fundentes em massas cerâmicas”, Cerâmica Industrial, v. 7, n. 3, pp. 33-36, mai./jun. 2002.

[12] ASSOCIAÇÃO BRASILEIRA DE NORMAS TÉCNICAS - ABNT, Classificação de pisos cerâmicos. Rio de Janeiro, 1997. 